\title{
New Center for Physician Rights
}

Cases of unfair physician treatment by regulatory boards and hospitals have been well publicized. However, little action to insure oversight of physician regulatory bodies has been done. Physicians who believe they have been subjected to unfair discipline now have a place to turn for information, advice, and support. The new center called The Center for Physician Rights (CPR) was founded by Kernan Manion, MD. According to their website the Center will offer:

1. Free confidential case review;

2. Case consultation and coaching;

3. Serve as a central authoritative informational and consultative resource;

4. Pursue organizational and legislative change.

CPR will develop an informational website and produce a monthly e-newsletter / blog updating subscribers of relevant developments. They hope to serve as the definitive "go to" knowledge resource by establishing a centralized reference library with essential resources based on their extensive research and cumulatively accruing knowledge of judicial decisions, case trends and operant medical licensing boards.

Manion's own career-ending experience with the North Carolina Medical Board (NCMB) was well publicized (1). His case dates back to September 2009, when he worked as a civilian psychiatrist under contract with the Deployment Health Center at Naval Hospital Camp Lejeune, in Jacksonville, North Carolina. After he raised concerns with the US Navy and a personnel contractor about what he believed was dangerously deficient care of active duty service members who had posttraumatic stress disorder, he was dismissed. Later an anonymous source raised concerns about his mental health, which resulted in an investigation by the North Carolina Medical Board. Although an independent, comprehensive psychological evaluation determined he had no mental disorder or other psychological impairment, an assessment by the Board concluded otherwise, and he was forced to deactivate his medical license. In 2016, he launched a lawsuit against the NCMB, which was ultimately unsuccessful on appeal because it exceeded the time limit for filing a petition. Manion blamed the NCMB for using stall tactics to delay the legal process.

Richard A. Robbins, MD

Editor, SWJPCC

\section{Reference}

1. Anderson P. One-Man Fight: MD Takes on State Medical Board, PHP. Medscape. November 8, 2016. Available at: https://www.medscape.com/viewarticle/871569 (accessed 11/13/18). 